\title{
MEASURING THE ENGAGEMENT OF IN-HOUSE CURRENCY SYSTEM USERS
}

\author{
Toshiomi Moriki ${ }^{1}$, Hiroki Satoh ${ }^{1}$, Shinpei Takami ${ }^{1}$, Kie Yoshiji ${ }^{1}$, Miho Kobayashi ${ }^{1}$ \\ and Norihisa Komoda ${ }^{2}$ \\ ${ }^{1}$ Research \& Development Group, Hitachi, Ltd., 1-280, Higashi-koigakubo Kokubunji, Tokyo 185-8601, Japan \\ ${ }^{2}$ Code Solutions, Co.,Ltd., Daidoseimei south building 9th floor, 1-2-11 Edobori Nishi-ku,Osaka, Osaka 550-0022, Japan
}

\begin{abstract}
With the recent outbreak of infectious diseases and the spread of remote work, there are concerns about the lack of communication among employees and the resulting loss of their motivation. In this paper, the design and effectiveness of the in-house currency system are reported, which is developed for the purpose of stimulating informal communication and mutual assistance among employees. In order to encourage employees to actively participate in the in-house currency system, user interactions are designed to foster empathy by visualizing the mutual aid behaviors of other employees in the system, in addition to small financial rewards. It has also a function that encourages solicitation among employees, inspired by events such as community contribution activities and other volunteer activities. The in-house currency system has been introduced to our R\&D department on a trial basis and evaluated the level of employee participation for about a year. As a result of analyzing the usage of 118 registered employees, it is observed that user engagement increases in the order of following steps; recognition of the in-house currency system, daily use of the system, and involvement of other employees.
\end{abstract}

\section{KEYWORDS}

In-house Currency System, Mutual Assistance, Engagement Measurement

\section{INTRODUCTION}

In corporate activities focusing on intellectual labor, (Nomura, T., 2002) are looking for ways to share knowledge possessed by employees and initiate innovation as an organization. In the context of so-called intellectual management, it is important to have a place and a method for sharing knowledge among employees.

In conventional Japanese companies, employees have gathered in a large office and have worked in groups to help each other (Furukawa, Y., 1998). While this traditional form of work is advantageous for knowledge sharing as employees can naturally overhear the phone call conversation and chats of those around them, it is also a hotbed of long working hours due to peer pressure (Nishida, Y. and Terashima, N., 2019). To deal with this problem, work style reforms have been implemented, and due to the recent epidemic of infectious diseases, remote works from home, hotel, and remote office are rapidly spreading.

In response to this situation, in-house currency systems (Tamura, K., 2018), (Kamii, M., 2019) have been attracting attention as one of the reward systems to promote a good culture of interaction and mutual help among employees and to improve employee engagement. In an in-house currency system, employees are given small monetary incentives that are accepted only within a specific organization. When introducing an in-house currency system, it is desirable to create a system that complements, not conflicts with, the company's conventional incentive systems, such as bonuses and awards. Specifically, in addition to notification from top management and administrative departments, it is necessary to successfully combine the involvement of other employees by advanced users (early adopters) who can use the in-house currency system at an early stage. However, there is a problem that a mechanism to objectively measure the effects of the introduction measures has not been established. 
Therefore, we have attempted to measure the amount of user engagement. In this paper, we describe the design of a service to promote the use of an in-house currency system, the construction of a user engagement measurement model, and an example of its application.

\section{THE IN-HOUSE CURRENCY SYSTEM AND ITS CHALLENGES}

\subsection{Overview of the In-House Currency System}

An in-house currency system is a reward system that issues a private currency, which is effective only within a specific organization. Although the amount of money in circulation and the scope of circulation are both limited, it is expected to promote actions that meet organizational goals, such as productivity improvement and organizational management facilitation, for employees and workers in the organization.

The functions of an in-house currency system are generally categorized into the following two types.

(1) Incentives to encourage favorable behavior from the company to the employees: incentive program type

(2) Message function to express gratitude for mutual help among employees: Peer bonus type

In this study, both functions will be included.

Figure 1 shows the overall picture of the services provided by the in-house currency system. The system is implemented on the mobile web application and the backend cloud service, which provides the intermediary between stakeholders and manages the currency. Users can access to this system via their own smartphone easily.

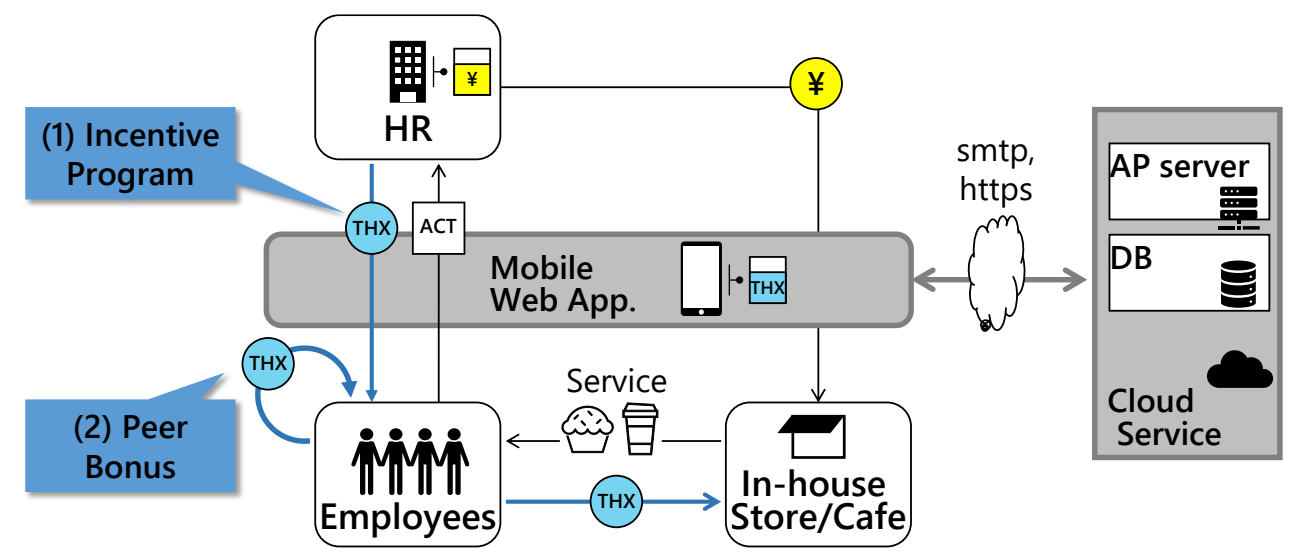

Figure 1. Service Overview of the In-house Currency System

The in-house currency insurance and consumption processes are like followings; (1) The company's management department, HR, issues virtual money named THX as an incentive program for employees' desirable mutual-help behavior (ACTION). Employees can be given THX for not only direct help but also for sympathetic behavior through (2) peer bonuses. The THX received can be used for payment at the company stores and cafeteria. 


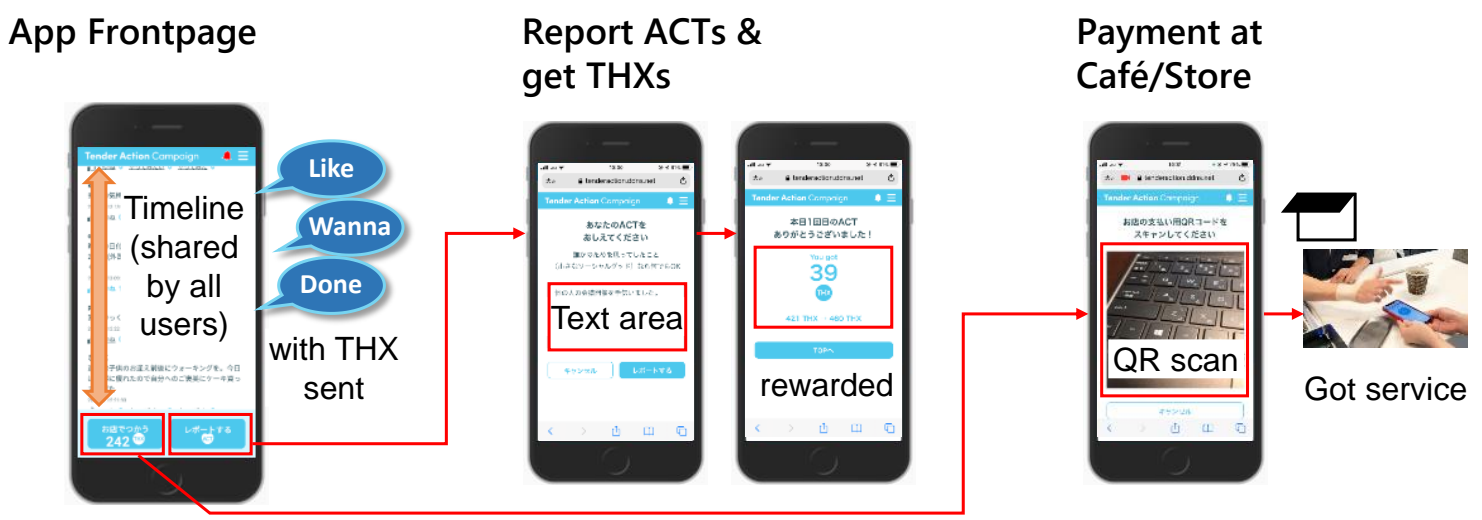

Figure 2. User Interface of the In-house Currency System

Figure 2 shows the screen images of the mobile web application that serves the user interface. At the App frontpage, users can see the timeline which contains recent mutual aid activities (ACT) by all users. If user get sympathies to other's ACT, he/she can make several reactions to others, such as "Like (I like this)", "Wanna (I want to do such a thing)", and "Done (I have done the same thing too)." Those reactions can be sent through this timeline with small THX attached - its for (2) peer bonus feature.

This frontpage has two main action buttons for subfunctions. Right one is for reporting ACTs and get THXs. This screen has a text area box to input the description of his/her ACT. Next, 39 ACT are sent to him/her a day for the reward - its for (1) incentive program.

Another button is for payment at in-house cafeteria and store. User can pay THXs for the service, like a cup of coffee, cookie, breads, and other daily materials. The application offers him/her the QR scan screen and he/she can pay any amount of THXs to get service.

\subsection{Challenges in Promoting the Use of In-House Currency Systems}

In this section, we examine the issues involved in implementing an in-house currency system. Table 1 shows a list of issues to be considered in order to increase the number of users who use this system on a daily basis (i.e., active users).

(a) Regarding the low threshold for starting to use the system, many people said that it would be good if there was some kind of mechanism to encourage participation from the company side. Specifically, it would be desirable if the work line of the employee's supervisor recommends participation, or if the benefits of participation are clearly stated for individual employees.

(b) It is difficult to devote a lot of time and effort to programs related to the in-house currency system because it is different from the main business. It is desirable to make it as easy as possible for novices to use the system in order to prevent them from leaving.

(c) Considering that it is a means of communication among employees, it is desirable to be able to see at a glance that others are using it even in a remote environment. It is also good to have an incentive to involve other employees.

Table 1. Issues in implementing an in-house currency system

\begin{tabular}{l|l|l}
\hline$\#$ & Issues & Description \\
\hline \hline (a) & $\begin{array}{l}\text { Barriers to involve } \\
\text { new users }\end{array}$ & $\begin{array}{l}\text { They need a good mechanism to encourage participation. Participation should be } \\
\text { encouraged via command channel, the benefits of participating as an individual are } \\
\text { easy to understand, etc. }\end{array}$ \\
\hline (b) & $\begin{array}{l}\text { Difficulties to continue } \\
\text { to use the app }\end{array}$ & $\begin{array}{l}\text { Since the program is different from the main task, it should be as easy to use as } \\
\text { possible. }\end{array}$ \\
\hline (c) & $\begin{array}{l}\text { Challenges of sharing } \\
\text { their activities }\end{array}$ & $\begin{array}{l}\text { It is desirable to be able to see at a glance that other people are using it, even in a } \\
\text { remote environment. It is better if there is an incentive to involve other employees. }\end{array}$ \\
\hline
\end{tabular}


The following are service policies to deal with the above issues and to increase the number of active users.

(a) Easy to enter: We make the service known on the company intranet and install signs as a permanent guide. We recommend that employees use nicknames instead of their real names, assuming that they are highly sensitive to others' opinions and privacy.

(b) Easy to use: Implemented as a mobile web application that does not require installation of any application as a touch point for users.

(c) Easy to spread to others: In order to feel the mutual activities of other users even in non-contact situations such as working from home, we can observe the timeline of all users' ACT reports, peer bonus sympathy, and THX giving. In addition, we provide time-limited reward program for recruiting new users.

\section{USER ENGAGEMENT MEASUREMENT MODEL}

An in-house currency system is generally a mechanism to promote communication among employees. It can be viewed as a network service closed to the company. In this section, we examine how to measure user engagement in order to promote the use of internal currency services by employees.

Research on user recognition of general services and promotion of their use has been widely conducted in the marketing field. AIDA (Rehman, F. U., Nawaz, T., Ilyas, M., \& Hyder, S., 2014) and AISAS (Xu, C., Hao, Q., \& Han, G., 2017) are well known as representative models. We refer to SIPS (Dentsu, 2011), (Luo, Z. 2018) a consumer behavior model derived from AISAS and published by Dentsu Co. Ltd. They assume that users recruit and involve other users by word of mouth and sympathy among themselves.

We were inspired by SIPS and assumed the following four steps in the usage of an internal currency service. We assume that user engagement will increase in the order from (i) to (iv).

(i) Employees are aware to the in-house currency service via intra media.

(ii) Registered as a user of the in-house currency service.

(iii) Reported ACT and earned incentives (THX).

(iv) Promoted the in-house currency service to other employees to attract new users.

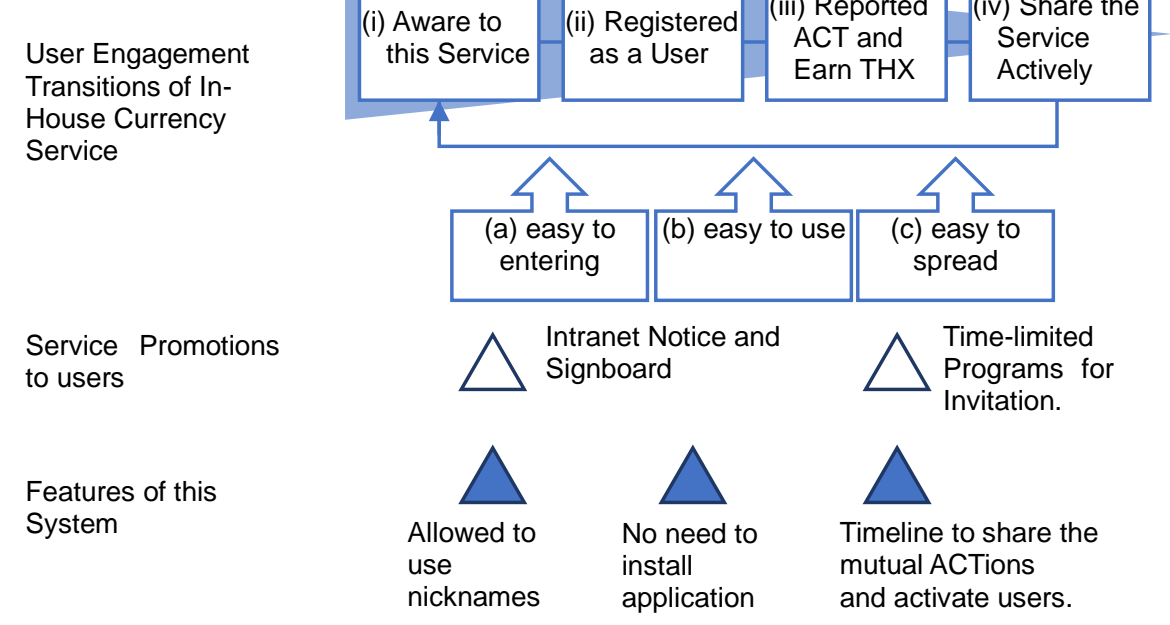

Figure 3. Measurement steps of Engagements of In-house Currency System

Figure 3 shows the relationship between the transition in user engagement and the measures taken to introduce the in-house currency system. We have planned the following (a)-(c) as measures for user acquisition. 
As a measure (a) to promote the transition from (i) to (ii), announcements are made on the company intranet and signs are installed as service measures. In addition, the use of nicknames in the system is recommended to prevent users from leaving the system.

As a measure (b) to promote the transition from (ii) to (iii), implement the system as a mobile web application that does not require the installation of an application, and make the operation as simple as possible.

As a measure (c) to promote the transition from (iii) to (iv), we offer rewards for soliciting other employees through a time-limited program. In addition, the timeline on the front page should be used to increase the number of active users by sharing the mutual aid activities of other users.

\section{ANALYSIS OF IN-HOUSE CURRENCY SYSTEM USAGE}

Based on the engagement measurement model described in Section 3-2, we analyzed the effect of the trial introduction of the in-house currency system.

The assumptions of the environment in the test are shown in Table 2. The test period started at April 2020, when work was basically prohibited due to the declaration of a state of emergency against the spread of COVID-19. The target office is the research and development division, and almost all of the approximately 700 employees are researchers and white-collar workers.

Table 2. Trial Environment of the In-house Currency System

\begin{tabular}{l|l|l}
\hline Trial Period & 2020/4/1 2021/3/29 (continued) \\
\hline \multirow{3}{*}{$\begin{array}{l}\text { Target } \\
\text { Organization }\end{array}$} & Type of organization & Research and Development \\
\cline { 2 - 3 } & \# of employees & 700 persons (approx.) \\
\cline { 2 - 3 } & Types of workers & White-collar workers \\
\hline \multirow{2}{*}{ Incentive Setting } & Incentive Amount & 39 THX per ACT (once a day rewarded) \\
\cline { 2 - 3 } & Peer Bonus Amount & 1 THX per Like (no limitation per day) \\
\cline { 2 - 3 } & Incentive Amount for Inviting a new user & 110 THX per each program. \\
\cline { 2 - 3 } & Where to use & In-house store and cafeteria \\
\hline
\end{tabular}

The incentive for the operation of the in-house currency system is to add 39 THX points for each act of mutual aid (ACT). This is equivalent to 39 yen. Peer bonus is given by returning three types of responses ("Like", "Wanna", "Done") to the ACT of others, and 1 THX is given for each responses. In general, the monetary incentives given are limited, and it is thought that users use this system mainly to enjoy communication with other employees.

Table 3 shows the transition of the status of user engagement during the test operation period. The number of user registrations (ii) and ACT-reported users (iii) increased rapidly from April 1, just after the service was launched, and increased to (ii) 84 and (iii) 55 as of May 27, when the emergency declaration corresponding to the infectious disease epidemic was lifted. During the declaration of the state of emergency, the business units to be tested were almost in a state of lockdown, but it is thought that effective advertising and promotion measures (a) and (b) were carried out.

After that, telecommuting was half enforced until the end of July, but from August 17, (c) a program to recruit new users was started. In October, several timed programs was conducted led by the administration department (HR) in order to encourage employees' volunteer and CSR activities. 7 users eventually shared and spread the program to other users, contributing to the acquisition of a total of 12 new users. 
Table 3. Transition of User Engagement Status

\begin{tabular}{l|c|c|c|c}
\hline Date & $\begin{array}{c}\text { (i) Aware to this } \\
\text { Service }\end{array}$ & $\begin{array}{c}\text { (ii) Registered as a } \\
\text { User }\end{array}$ & $\begin{array}{c}\text { (iii) Reported ACT } \\
\text { and Earn THX }\end{array}$ & $\begin{array}{c}\text { (iv) Share the } \\
\text { Service Actively }\end{array}$ \\
\hline $2020 / 4 / 1$ & 700 & 17 & 5 & 0 \\
\hline $2020 / 5 / 27$ & 700 & 84 & 55 & 0 \\
\hline $2020 / 8 / 5$ & 700 & 92 & 57 & 0 \\
\hline $2020 / 10 / 14$ & 700 & 104 & 60 & 7 \\
\hline $2021 / 3 / 29$ & 700 & 118 & 61 & 6 \\
\hline Note & (Approx.) & \# of users registered. & $\begin{array}{c}\text { \# of users reported } \\
\text { an ACT or more. }\end{array}$ & $\begin{array}{c}\text { \# of users invited } \\
\text { new users. }\end{array}$ \\
\hline
\end{tabular}

Figure 4 shows the engagement breakdown of the number of users during the test implementation period of the in-house currency system.

Within the first month of the test introduction of the in-house currency system, the number of users who completed the registration (ii) reached 84 , and the number of users who reported the ACT and participated (iii) reached 55, indicating that the initial measures (a) to lower the threshold for starting to use the system and (b) to make the system easy to use were generally successful. After that, the number of newly registered users of (ii) increased steadily due to (c) measures to make it easier to spread the service to other people, and finally 118 users were acquired.

On the other hand, the number of users in the stage (iii) after May did not grow much, and it turned out that almost half of the registered users in the stage (ii) had never reported an ACT finally. This implied that the users might be fixed who reports ACTs and sends Likes repeatedly.

In order to understand the transition to the step (iv): sharing and spreading, we added a function in mid-August that allows new employees to report the email address of the solicitor when they register as a user. As a reward for solicitation, 110 THX is distributed to both new registrants and solicitors. As with the step (iii) users, we have not observed any new transitions to the state (iv) since December, and it is necessary to take act including advertising measures.

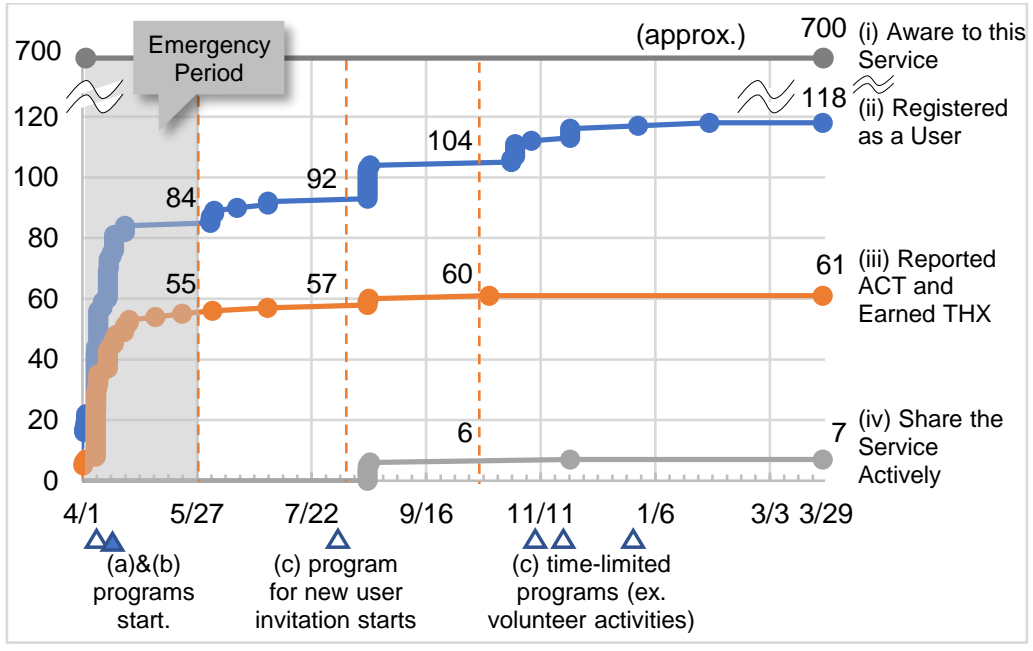

Figure 4. Trends in the breakdown of the number of users 


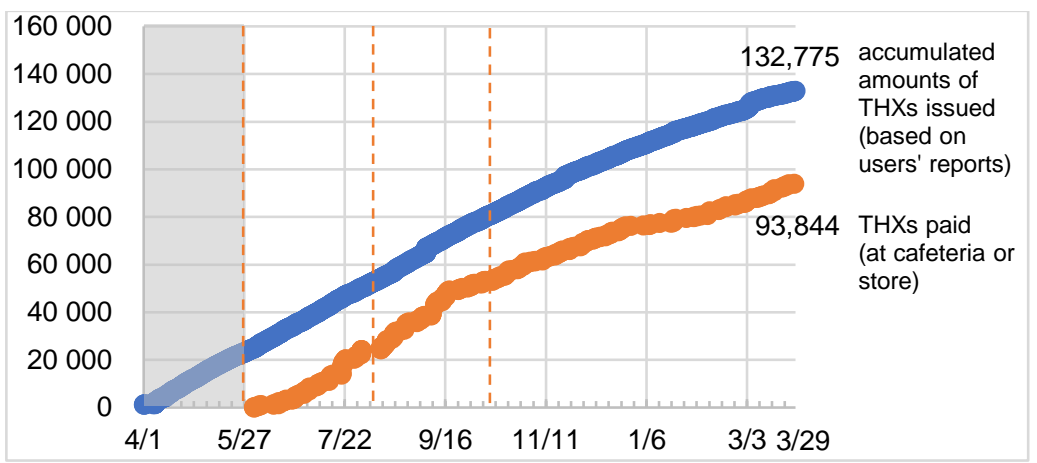

Figure 5. Trends of accumulated THXs issued and paid by the in-house currency system

Figure 5 shows the trend of THX issuance and paid by users throughout the experimental period. Throughout the experimental period, users reported ACTs stably, and the issuance of THX increased almost linearly. The company paid out 366 THX per day on average, which means that 9 to 10 people reported their ACTs. Payments by users at the cafeteria and concession stands have been made since June, after the state of emergency was lifted.

The payments have been made sequentially following the issuance of THX, but some of the payments are still pending and have not been paid from user accounts. As a result of the user interviews, some users answered that they look forward to acquiring THX itself, and it is possible that user preferences are leading to the withdrawal of THX.

Figure 6 shows the frequency distribution of the price per unit of THX acquisition and payment by users. $39 \mathrm{THX} /$ day was used in most cases for THX acquisition, but some users paid a higher price due to the timed program (c) for acquiring new users and interviews with users about their usage. In addition, many users reported ACTs with $\mathrm{THX}=0$ (i.e., more than two reports per day), suggesting that employees report each other's supportive behavior even when there is no monetary reward.

Payments at the cafeteria and store peaked between 120 and 150 THX, and continued to grow steadily thereafter to around $570 \mathrm{THX} /$ payment. This suggests that users are making THX payments for every 3 to 10 or more ACT reports.

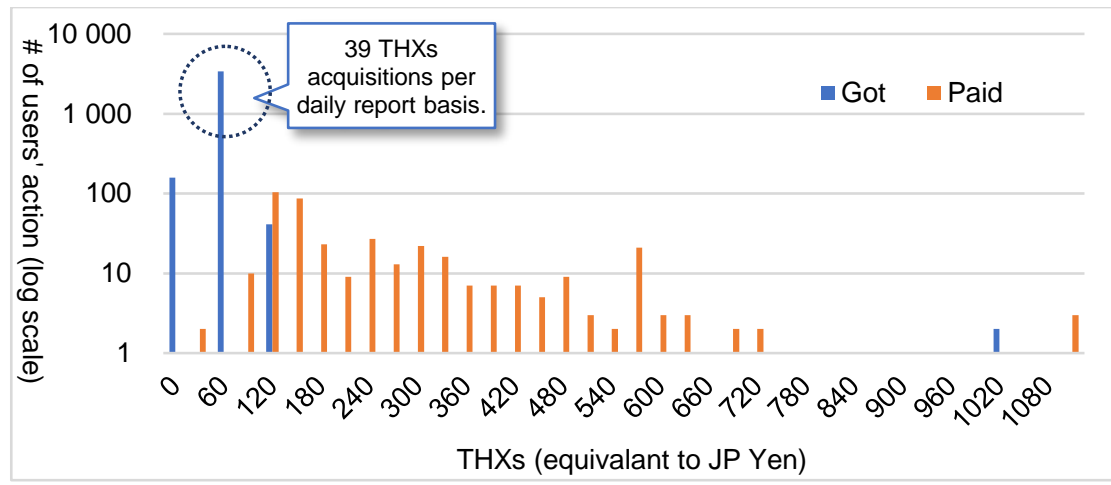

Figure 6. THX amounts per each action (got or paid)

\section{CONCLUSION}

An in-house currency system has been developed and implemented at a research and development department. More than 100 employees are involved though a 12-month trial. By analysis of the usage of the system, it is suggested several findings such as that more than $70 \%$ of user registrations were done during the 
first 2-month, even under the emergency declaration period. It might be a good aspect of the in-house currency system implementation, which needs no face-to-face communication between users.

By the analysis of issuance and usage of the in-house currency, active users reported several mutual activities a day regardless the financial rewards. Their payment amounts varied depending on users. With the invitation program for new user acquisition, highly engaged users have involved new users but the number of them were limited throughout the trial period.

\section{REFERENCES}

Dentsu, 2011, SIPS, [online] Available at https://www.dentsu.co.jp/news/release/pdf-cms/2011009-0131.pdf [Accessed 24 May 2021]. (in Japanese)

Furukawa, Y., 1998, Office Design and Communication in Japanese Corporations, Journal of Policy Studies 6, 1-20. (in Japanese)

Kamii, M., 2019, Introduction of intra-facility currency to enhance social participation and proactive behavior, Congress of the Japanese Physical Therapy Association 46S1(0), G-78_2. (in Japanese)

Kijima, K., 2015. Translational and trans-disciplinary approach to service systems. in Service systems science (pp. 37-54). Springer.

Luo, Z. 2018, The Consumer Behavior Analysis under Large Data Environment. in Proc. of 2017 5th International Education, Economics, Social Science, Arts, Sports and Management Engineering Conference (IEESASM 2017), pp.334-339.

Nishida, Y. and Terashima, N., 2019, Japanese work style and "Work-style reform": The problem of reducing long working hours and introducing telework, Psychologist: bulletin of the Graduate School of Professional Clinical Psychology, Kansai University, (9), 61-69. (in Japanese)

Nomura, T., 2002, Design of 'Ba' for successful Knowledge Management? how enterprises should design the places of interaction to gain competitive advantage, Journal of Network and Computer Applications, 25(4), pp.263-278.

Novani, S., Cintyawati, C., \& Mayangsari, L., 2018, Back to the Future: A Revelation of Conventional Platform Preference of Digital Creative Ecosystem Entities in Bandung. in Collaborative Value Co-creation in the Platform Economy (pp. 247-268). Springer.

Rehman, F. U., Nawaz, T., Ilyas, M., \& Hyder, S., 2014, A comparative analysis of mobile and email marketing using AIDA model. Journal of Basic and Applied Scientific Research, 4(6), 38-49.

Tamura, K., 2018, Eliminating waste and optimizing manpower and equipment! DISCO's mysterious " in-house currency operation", Nikkei Top Leader, 402, pp.76-82. (in Japanese)

Xu, C., Hao, Q., \& Han, G., 2017, Research on the marketing strategy of the new media age based on AISAS model: A Case study of micro channel marketing. in Proc. of the Fourth International Forum on Decision Sciences (pp. 477-486). Springer. 